\title{
Critical stance within a community of inquiry in an advanced mathematics course for pre-service teachers
}

\author{
Simon Goodchild ${ }^{1}$ D Naneh Apkarian ${ }^{2} \cdot$ Chris Rasmussen $^{3} \cdot$ Brian Katz $^{4}$ \\ Published online: 16 March 2020 \\ (C) The Author(s) 2020
}

\begin{abstract}
This paper reports a study of university students' experiences of learning mathematics in an introductory differential equations course that takes an inquiry approach to learning and teaching. The students are on a trajectory leading toward a bachelor's degree in mathematics to be followed by a year-long teacher education credential program. The analysis of students' end of course presentations and written portfolios is framed with community of practice theory, complemented with analytic categories from community of inquiry, including notions of inquiry stance and critical alignment. Our social theorization of university mathematics education adds a complementary perspective to the more conventional cognitive and discursive analyses and is necessitated by the very nature of inquiry approaches to education. The analysis of students' presentations and writing leads to exploring their development of the notion of critical stance, which the students are seen to take toward the mathematics, their learning, and approaches to teaching mathematics. We find that the notion of critical stance can be distilled into three components: awareness, self-evaluation, and agency.
\end{abstract}

Keywords Community of practice $\cdot$ Critical alignment $\cdot$ Critical stance $\cdot$ Inquiry-based mathematics education

\section{Introduction}

In this paper, we use community of practice theory (CPT) as an overarching framework to explore the mathematics education of university students who intend to become secondary school mathematics teachers. CPT has been used as a framework to analyze and explain participation in mathematics teaching in school (Jaworski 2006), in school teacher education (e.g., Goos and Bennison 2008), and in school teaching development (Nickerson and

Simon Goodchild

simon.goodchild@uia.no

1 University of Agder, Postboks 422, 4604 Kristiansand, Norway

2 Western Michigan University, Kalamazoo, MI, USA

3 San Diego State University, San Diego, CA, USA

4 Smith College, Northampton, MA, USA 
Moriarty 2005; Solomon et al. 2017; Zaslavsky and Leikin 2004). It has not, however, been used extensively in the context of university mathematics teaching. A sizable proportion of research in undergraduate mathematics education has focused on mathematical concepts and communication, thus leading researchers to adopt theories of cognition and discourse.

In this paper, we analyze participation in a university mathematics course for pre-service teachers within a CPT framework and report on students' adoption of a "critical stance" toward mathematics, their own learning, and teaching. The conventional approach adopted by many university mathematics teachers who perceive their purpose is to model authentic mathematics through lecture (London Mathematical Society 2010). From such a perspective, it is of little interest to examine issues of teaching and learning within a social practice theoretical framework. However, there is growing use of active learning approaches to university mathematics education. In North America, for example, Stains et al. (2018) identified the use of active learning approaches in undergraduate mathematics more than other undergraduate STEM courses. Moreover, there has been considerable endorsement of such strategies by professional organizations (e.g., Conference Board of the Mathematical Sciences 2016; Mathematical Association of America 2017; Saxe and Braddy 2015), challenging the dominant paradigm of modeling by lecture. All this precipitates a need to develop the social theorization of university mathematics education. Addressing this need is a primary goal of this paper.

In particular, we explore eight students' development of critical stances in a small inquiry-oriented differential equations course for future secondary mathematics teachers. These critical stances are one aspect of a community of inquiry, which is a particular kind of community of practice wherein members inquire into the nature of their shared practice and critique it. Our work confirms that an inquiry-oriented classroom can be studied as a community of practice and that the teaching approach can support students' development of critical stances toward mathematics itself, the learning of mathematics, and the teaching of mathematics-which are three major elements of university mathematics education trajectories.

\section{Theoretical background}

Theorizing teaching and learning mathematics at university within a CPT framework begins by conceptualizing teaching, learning, and doing mathematics as an enterprise in which participants engage either as learners on an inward trajectory of participation or as full participant members (teachers and researchers). Figure 1 depicts our meaning for the enterprise of university mathematics education, which is composed of several interacting activities: learning, doing, teaching, and researching. Students enter the practice and embark on an inward trajectory of participation, beginning as learners, and if they were to stay within the practice of university mathematics education, full participation would entail teaching and research in varying proportions. The students whose practice we describe in this paper are following a program aimed at schoolteacher education. These students would, for part of their experience, work across two practices-school mathematics education and university mathematics education. Indeed, any program that includes a period of internship or practicum outside the university crosses boundaries as students experience the different practices. Except for the few students who follow an uninterrupted trajectory toward research and teaching within the university, students break out of the practice of 


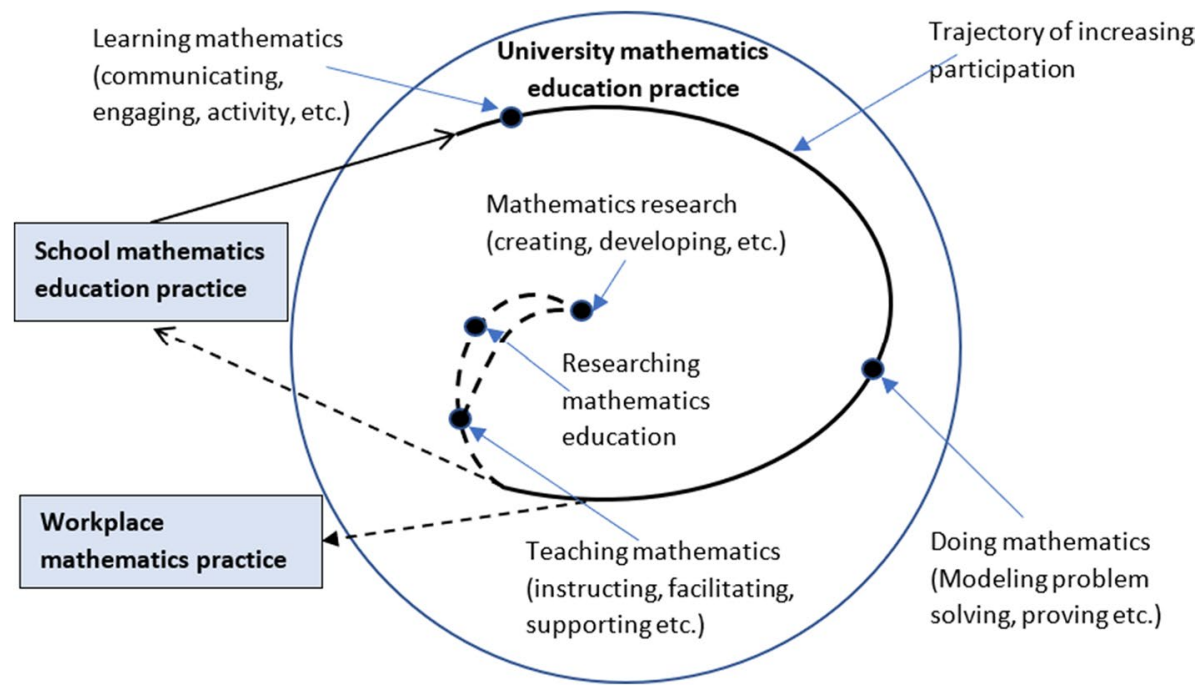

Fig. 1 The practice of university mathematics education: doing, learning, and teaching mathematics

university mathematics to embark on another inward trajectory in employment such as school teaching or mathematician in industry or commerce.

The community of participants is bound together by their mutual engagement and the shared repertoire ${ }^{1}$ that develops through their participation. Mathematics and mathematical practices are reified through the objects and processes of mathematics (e.g., representation, algorithms, theorems and proofs) and the resources used in communicating mathematical ideas. Later in this paper, we develop from Wenger's (1998) articulation of CPT three strands of the practice that are fundamental to our analysis: understanding, learning, and teaching that are based on notions of participation-reification, enterprise, engagement, and repertoire. We reflect on these three strands within the respective sections of the analysis because of the symbiotic relation between theory and analysis of evidence of participation.

Of the sparse research using CPT in the undergraduate context, some have focused on communities of mathematics instructors. For example, Viirman (2018) reports on a collaboration between mathematicians and mathematics educators in which a mathematics educator functioned as a broker, influencing a mathematician's instructional practice. Jaworski and Matthews' (2011) study of mathematics lecturers suggested that teaching did not function as a joint enterprise of the community, ${ }^{2}$ though the instructors had a shared repertoire and mutual engagement; Rasmussen et al. (2009) identified an instructor's brokering moves in an inquiry-oriented classroom which bridged students' small groups, the larger classroom community, and the broader community of mathematics as a whole. Others have, as

\footnotetext{
1 Following Wenger's articulation of community of practice theory we explain "mutual engagement" in terms of participants collaborating with complementary skills, routines and actions to achieve the shared goals of the enterprise (university mathematics education); and their "shared repertoire" as comprising the discourse composed of special terms and expressions, shared artefacts, instruments, routines and experience that facilitate the attainment of the shared goals.

2 Joint enterprise, university mathematics education is more generally the set of interconnected activities in which participants negotiate and combine competencies, effort and accountability to achieve shared goals.
} 
we do in this paper, focused on students. There is also evidence that the practice of mathematics at the postsecondary level is distinct from that at other levels (e.g., Holton 2001; Ticknor 2012). Solomon (2007) suggests that first-year mathematics lectures have not positioned learners as legitimate peripheral participants in the practice of mathematics. ${ }^{3}$

One previous and important contribution to the field that adopts CPT as a framework for exploring university teaching and learning is provided by Biza et al. (2014), upon which our paper builds. To theorize university classroom practices that set out to be inquirybased, Biza et al. (2014) go beyond CPT as set out by Wenger (1998) and Lave and Wenger (1991). They propose that when students adopt an inquiry stance, the enterprise, students' engagement, and their shared repertoire all become transformed by inquiry. Consequently, the community of practice $(\mathrm{CoP})$ is transformed into community of inquiry $(\mathrm{CoI})$. A key element in this transformation is that the mode of belonging to the community, alignment, described by Wenger as "do(ing) what it takes to do our part" (Wenger 1998, p. 179) is transformed into a form of critical alignment. As explained by Biza et al. (2014),

In a CoI, alignment is always critical alignment, by which we mean that as a normal part of their participation, participants question the practices in which they engage. Such questioning leads to new forms of practice, new modes of awareness of the problems and issues in developing effective ways of working, and good outcomes for students' learning. (p. 164)

In this paper, we develop the notion of students adopting a critical stance toward their engagement in mathematics learning and teaching when they are critically aligned to the practice of mathematics education in the sense that Biza et al. describe above. In particular, we draw on the following definition of critical stance put forth by Curzon-Hobson (2003, p. 201): A critical stance is "an attitude or disposition towards oneself, others and the object of inquiry that challenges and impels learners to reflect, understand and act in the milieu of potentiality." Critical alignment and critical stance are complementary constructs. Following Wenger's analysis of alignment, critical alignment is a "mode of belonging" relating to participation within a CoI, and this is evident in the above quote from Biza et al. By contrast, critical stance is a mode of being, and as Curzon-Hobson's definition indicates, critical stance is an attitude or disposition and a critical awareness and reflection on one's own experience, meanings, and knowing. We therefore distill this characterization of critical stance into three key features: students' awareness, students' self-evaluation, and students' judgment and agency.

There are thus three major components or conditions for students to adopt a critical stance. First, the students must be aware of the possibility that their experience of the practice could be different, for this they need to experience variety: in forms of engagement and participation, in the way mathematics is reified, and in terms of the way the enterprise is designed and implemented by the teacher. Second, the students must be able to reach some judgment, based on their reflection and evaluation of experience of participation. The students must be able to recognize when one experience of meaning, learning, or teaching is better, deeper, richer, more profound, etc., than another. Third, the students need

\footnotetext{
3 Peripheral participants: As new members join an established practice they are yet to develop the range of competencies and repertoire required to engage fully in the enterprise. Their newcomer status is accepted (ie. as legitimate) into the practice with a partial role that gradually increases as they appropriate the competencies and repertoire of the practice. They join on the edge (periphery) and embark on an inward trajectory to become fully functioning participants in the practice.
} 
to be aware of their agency to change things (for the better) through the manner of their engagement. Biza et al. (2014) argue that critical alignment arises from "inquiring into the teaching-learning process to achieve 'better' outcomes from it, taking an 'inquiry stance' in practice ..." (p.164). Our notion of critical stance includes and goes beyond mathematical inquiry as students' agency includes and goes beyond mathematical questioning into questioning practices. In an invited reaction to Biza et al. (2014), Goodchild (2014) questions "whether it is possible to design a $\mathrm{CoI}$ in which students can be genuine participants; and, if it is, what are the conditions that ensure such participation?" (2014, p. 180). The three conditions for taking a critical stance outlined in this paragraph go beyond "inquiry stance" and "critical alignment" and thus go some way toward answering these questions; further we claim that in this report we demonstrate how these conditions can be met within a mathematics course for pre-service teachers.

In our analysis, the construct critical stance emerged from an examination of students' engagement in a mathematics class in which the teacher had the development of an inquiryoriented classroom as a key educational goal. Inquiry was conceptualized as students' deep engagement in mathematics, peer-to-peer interaction about their mathematical thinking, and teacher interest and use of student thinking (Laursen and Rasmussen 2019; Rasmussen and Kwon 2007). The examination of students' productions set out initially to expose evidence of a community of inquiry as described by Biza et al. (2014); however, the analysis, which we describe below, drew attention to the three conditions: awareness of possibilities; reflection, self-evaluation, and judgment; and agency and thus to the notion of critical stance. In this paper, we bypass the initial approach to the data and focus on addressing directly the question:

What characterizes the critical stance taken by students in this class?

We next describe the classroom context and naturalistic approach to expose the nature of the critical stance taken by students.

\section{Classroom context and method}

\section{Classroom context}

The content of the course was differential equations, with an emphasis on modeling and graphical, numerical, and qualitative approaches. Unlike a conventional, technique-driven treatment, which might be of questionable value for pre-service teachers, this course embraced the mathematical practices that these future teachers will be expected to enact in their own classrooms (see Common Core State Standards Initiative (CCSSI) 2010) and explicitly sought to deepen students' understandings of function and rate of change, key concepts in secondary school mathematics. There were eight third-year or fourth-year undergraduate mathematics majors enrolled, all of whom were intending to be secondary school mathematics teachers. In contrast to much of these students' previous experiences in undergraduate mathematics, the instructional format featured cycles of students working collaboratively in small groups followed by whole-class discussions and student presentation of small group work. Very little lecturing occurred, but the teacher did insert information and make connections to conventional or formal terminology in response to students' mathematical work. There are two distinguishing educational goals of the course, one related to classroom discourse and the other related to the mathematics. An explicit goal of 
the teacher was to promote particular social and sociomathematical norms which connect to students' beliefs about mathematics and what it means to learn mathematics (Yackel and Cobb 1996). Specifically, the teacher was intentional in fostering the social norms that students explain and justify their thinking, however tentative, listen to and attempt to make sense of others' thinking, and indicate agreement or disagreement (with reasons) with others' reasoning. The primary sociomathematical norm of interest was that justifications be based on underlying concepts as opposed to appeals to procedures or external authorities such as the text or teacher. The teacher took the view that norms are not rules set out in advance, but rather are constituted and reconstituted through interaction.

These discourse goals were complemented by mathematical goals of students learning the mathematics with meaning via a sequence of challenging problems. The InquiryOriented Differential Equations curriculum (Rasmussen et al. 2017) was inspired by the instructional design theory of Realistic Mathematics Education (Freudenthal 1991; Gravemeijer 1999) in which mathematics is first and foremost conceptualized as a human activity of sense making and mathematizing (as opposed to an a priori collection of predetermined facts and procedures). For example, the curriculum engaged students in a sequence in which they reinvented a bifurcation diagram (Rasmussen et al. 2019). The goal here, as with other important concepts and methods for analyzing differential equations, was that students would come to view the mathematics as emerging from their individual and collective efforts.

\section{Methods}

We take a naturalistic approach to address the question posed above, that is the data are generated from the student artefacts that are produced in the regular activity of the classroom, and the research has not demanded anything that was not intended for teaching and learning. Two main sources of data used are students' end of semester portfolios and videos of corresponding oral presentations of student-selected items from their portfolio. The end of the semester portfolio assignment required students to select seven items that they felt showcased their progress and accomplishments since the midterm. Typically, an item selected was a particular problem or small number of related problems. Students were instructed to select items that they felt highlighted their creativity or inventiveness, their mathematical growth, their ability to connect ideas/concepts, their deep understanding of concepts, and their ability to model with mathematics, reason mathematically, etc. For each item selected, they were required to write a rationale that explained why they selected this particular item(s) and the personal significance of the item. In addition to submitting the portfolio, each student was required to prepare and present a 15-min oral presentation with powerpoint highlighting three items of their choice. Students consented in writing for their anonymized portfolios and transcripts of the videos of oral presentations to be used in this study.

The data were analyzed using thematic analysis (Braun and Clarke 2006), which involved an iterative process that moved between data, theory, and interpretation, with cycles of researchers' individual and group engagement. The team of four researchers, which includes the course teacher, first created transcripts of the students' oral presentations. This was subsequently coded by three members of the team separately using categories from Wenger's (1998) account of community of practice: joint enterprise, mutual engagement, and shared repertoire. Individual coding decisions were then the subject of extensive discussions by the research team. Concurrent engagement with the literature 
applying CPT to educational settings led the team to reflect on the substantive question: what are the grounds for claiming that the class had developed into a community of inquiry? At this point, the theorization provided by Biza et al. (2014) became the key to our interpretation as we looked for evidence of critical alignment.

In our initial analysis of the oral presentations, we were surprised to find students offering, in addition to reflections on their mathematical progress and accomplishments, personal reflections on their learning experiences in the course, despite the fact that the portfolio instructions focused on mathematical aspects. These unexpected reflections from students prompted us to then consider more deeply the notion of critical stance. Consequently, we turned to the students' portfolios and presentations and began to operationalize the dimensions of critical stance that forms the substance of the analysis and interpretation that follows. Three principal strands of students' critical stance emerged: toward their understanding of mathematics, toward their approach to learning mathematics, and toward approaches to teaching mathematics. The next section is organized to set out the theorization and evidence for these three strands.

\section{Results}

As a reminder, the research question is: What characterizes the critical stance taken by students in this class? Our analysis reveals three areas in which students take a critical stance: toward mathematics; toward learning mathematics; and toward mathematics teaching. These areas align with the first three steps of the trajectory depicted in Fig. 1: the learning, doing, and teaching of mathematics. Thus, the foci of these critical stances are not surprising, and our key contribution is providing evidence of students' development of true critical stances in all three areas. In developing these results, we illuminate the three conditions of taking a critical stance: awareness that experience can be different, reflection on experience and a sense of judging the quality of that experience, and the sense of agency to make improvements.

\section{A critical stance toward mathematics}

Two issues are at stake when taking a critical stance toward mathematics: taking a critical stance toward understanding of the mathematics content encountered and taking a critical stance toward the nature of their participation in mathematics. First, we look at the notion of understanding within CPT. Wenger argues that terms such as knowledge and understanding "require some caution because they can easily reflect an implicit assumption that there is some universal standard of the knowable" (Wenger 1998, p. 41). An example of an implicit assumption that Wenger wants to avoid, for example, would be the notion that there exists a universal standard of a comprehensive knowledge of the concept of derivative $(\mathrm{d} y / \mathrm{d} x)$. From a purely theoretical perspective, such standards may exist in mathematics. However, there is no way that any one person can truly know whether their understanding, or anyone else's for that matter, matches a possible theoretical universal standard.

In CPT, Wenger therefore frames understanding not in terms of some universal standard but in terms of meaning, experience, and negotiation in the world. When students participate in the differential equations class they engage in the enterprise and develop a shared repertoire, they respond to tasks, and they reflect on the meanings they develop. Their 
activity as a student intersects with the work of mathematicians and mathematics teachers. In this context, they develop a relation with mathematics and with mathematics education, and in the case of these students, they develop their identity as learners and as future mathematics teachers and educators.

Mathematics is reified through the classroom tasks and discussion, through the procedures, representations and transformations, patterns, relationships and connections, theorems and proofs, language, skills, and competencies that compose the repertoire of mathematics education practice. The students experience meaning through their negotiation of participation in the multilayered practice of the mathematics class and the multi-dimensioned repertoire and reifications of mathematics. For example, this is illustrated when Carly (all names are pseudonyms) reflects on a problem related to the uniqueness theorem:

In light of the uniqueness theorem, consider the population model $\frac{\mathrm{d} P}{\mathrm{~d} t}=0.3 P\left(1-\frac{P}{12.5}\right)$. If $P(0)<12.5$, will the population ever reach 12.5? Explain.

I struggled with understanding the theorem when we went over it in class so that is why this problem was initially difficult. Once I looked at the question and theorem again I was able to make a better connection. (Carly, Portfolio)

Students reflect on experience of participation in classroom activity that enables them to negotiate a fresh relationship ("better connection") with objects within the mathematics repertoire, such as a theorem. Carly describes her experience as a "struggle with understanding." Interestingly, she does not claim at the end to understand (even if Carly had claimed a perfect understanding, it would be challenged on the basis of the previous argument: how can she know?), but her claim to make better connection does reveal a growth in what the theorem means to her.

To adopt a critical stance toward understanding requires students to have experienced over time meanings that give the potential of different degrees of understanding. Thus, Abel can observe "my understanding grew" (Portfolio); and Brad "Just because I thought I fully understood a concept doesn't mean I actually did" (Portfolio); and Enrique reflects on an experience with a task related to cooperative and competitive populations, Bees and Flowers:

Bees and Flowers

Often scientists use rate of change equations in their study of population growth for one or more species. In this problem we study systems of rate of change equations designed to inform us about the future populations for two species that are either competitive (that is both species are harmed by interaction) or cooperative (that is both species benefit from interaction).

Which system of rate of change equations below describes a situation where the two species compete and which system describes cooperative species? Explain your reasoning.

(i) $\begin{array}{lll}\frac{\mathrm{d} x}{\mathrm{~d} t}=-5 x+2 x y & \text { (ii) } & \frac{\mathrm{d} x}{\mathrm{~d} t}=4 x-2 x y \\ \frac{\mathrm{d} y}{\mathrm{~d} t}=-4 y+3 x y & & \frac{\mathrm{d} y}{\mathrm{~d} t}=2 y-x y\end{array}$

[O]ur understanding was still underdeveloped ... this whole process put me in a mental state to try to think of the problem critically creatively and with meaning rather than more robotically trying to just solve a problem without knowing what is going on. (Enrique, Portfolio)

Variation opens the possibility of awareness, which needs to be realized through reflection; awareness that something might be experienced differently is the foundation of a 
critical stance. A further requirement of a critical stance, if it is to be a positive experience, is the student's sense of agency, that they can make a difference. Enrique implies his sense of agency as he acknowledges that he was placed in a "mental state" in which he was required to "think of the problem critically creatively". In the case of these students, they are empowered to negotiate new meanings through developing new relationships between their participation in the class and reification of the mathematics studied, and this is explored further in next section (Critical stance toward learning/being a learner of mathematics).

In the quote above, Enrique uses the term "robotically." Perhaps in the repertoire of mathematics education research this would be translated as "procedurally." While we as researchers can reasonably infer what Enrique means when he uses the term robotically, our inferences are more limited when they use words such as understanding, meaning, critical thinking, and so on. Nevertheless, it is possible to identify a common theme that both illustrates and confirms the development of understanding as an accumulation of meanings that emerges from the relation between participation and reification as outlined above. The students experience the mathematics through a variety of representations (reifications) and forms of participation (problem solving in groups and alone, discussing, presenting, reflecting and writing). The students express their growth of understanding in terms of increased or better connections.

An intriguing set of problems that culminated all our growth, knowledge, which highlights critical thinking, ability to make connections. (Enrique, Portfolio)

So that was one of my most proudest works. I felt like I really understood the question and I understood my answer and I felt that I made really clear connections and I was really proud of it. (Jimena, Presentation)

In the excerpt above, Jimena is referring to her response to an examination question in which a model of a fish population is provided: and the problem is to comment on a suggestion for an initial population range to ensure that the stock increases. In her presentation of this entry, she reflects how she identified equilibrium solutions and related different graphical representations to identify the points within a given range at which an initial population would increase or decrease.

In the next excerpt, Brad reflects on his experience from a task about the rate of cooling of a cup of coffee and a question about whether two cups with different initial temperatures will ever be at exactly the same temperature. Whereas some students refer to connections (e.g., see previous quote from Carly, Portfolio), Brad describes his experience as seeing concepts tied together.

Once you learn a concept it does not just go away, rather you continue to build upon it and find that it ties together with other concepts (Brad, Portfolio)

In terms of students' experience of meaning, the connections can arise in different ways, they might be different reifications (representations) of the same concept or they could relate to how a single reification can give rise to different experiences (tasks and activities) in which students participate. Brad appears to recognize this when he reflects:

When this class first started, I never would have imagined that a differential equation could take on so many different meanings. My first initial thought that the term dy/dt only meant the derivative of dy over the derivative of $t$ [sic]. Boy did I come to realize, that I was only scratching the service [sic] of all dy/dt stood for. (Brad, Portfolio) 
When the students claim to understand a concept in a new light, they are probably referring to new connections and relationships that have opened up for them. For example, when Valencia claims to "understand the concept a lot better" (Valencia, Portfolio), or Carly, to "have a stronger understanding" (Carly, Portfolio), or when Brad contrasts understanding on the surface and on a full conceptual level:

Just because I think I have a concept understood on the surface, does not mean that I have it completely understood on a full conceptual level. (Brad, Portfolio)

So far, the discussion has focused on students' experience of mathematical meanings. As they develop new meanings, they reflect critically (in a negative sense) on the limitation of the prior meanings they held (surface/scratching the surface (superficial), robotic (procedural), memorization without meaning, etc.). Being critically aware of variations in understanding, and about limitations of restricted knowledge, and participating in a practice in which they are expected to be agents of their own development enable the students to adopt a critical stance toward the mathematics they are learning. However, the experience also affects their relationship with mathematics as a discipline, their awareness of the nature of mathematics and learning mathematics. Thus, Brad claims:

Everything you learn in mathematics can always be expanded on and joined with other concepts, it all ties together one way or another. (Brad, Portfolio)

The students' critical stance toward mathematics as a discipline is established on a repertoire of learning mathematics that indicates one's meanings are not all there is to understand, that one can extend personal meanings through new relations between layers of participation and dimensions of reification.

\section{Critical stance toward learning mathematics}

In this section, we consider the ways in which students took a critical stance toward learning mathematics. In particular, this stance is manifested in regards to both the process of learning mathematics and what it means to be a learner of mathematics. Using Wenger's (1998) communities of practice theory, we discuss in essence what students learned about learning. We begin with a discussion of what learning is from a community of practice perspective as well as other commonly held beliefs about learning mathematics, and how a critical stance toward learning might be identified.

In the epilogue of Communities of Practice, Wenger (1998) summarizes his social perspective on learning: "Learning-whatever form it takes — changes who we are by changing our ability to participate, to belong, to negotiate meaning. And this ability is configured socially with respect to practices, communities, and economies of meaning where it shapes our identities" (ibid., p. 226). This summary is accompanied by a set of twelve principles. We do not reproduce the list here, but highlight two relevant aspects. First, learning is fundamentally experiential and fundamentally social. These students' practice as learners developed over many years of participation in school, two to three of which were at this same university and with many of the same peers in their major. By this time, they had established expectations for their role in the classroom, their relationship with the teacher, how to gauge their success, and what the goals are. Second, learning is a matter of engagement. As learning depends on opportunities to contribute to the practice, students in this course were well-positioned to further develop their identities as learners. In particular, Wenger notes that this engagement involves integrating the enterprises of "communities 
that we value and that value us" (p. 227) and to make use of those communities' repertoires as our own. Again, as this course was for prospective mathematics teachers and the teacher a mathematics education researcher, the interaction of a community of (undergraduate) learners with a community of dedicated educators provides the possibility to generate new learning about learning.

In what follows, we give evidence that students, by the end of the course, took a critical stance toward their learning of mathematics. In particular, we identified two themes: learning with meaning and learning as an active process. We do not require that students describe learning as we have done, using Wenger's principles; nevertheless, it is illuminating that many of their critical stances signify a shift toward learning as something that is more experiential, social, and engaged. Instead, we look for explicit attention to the learning process by students, as indicative of an (emerging) critical stance. That attention was apparent if they reflected on the learning process (rather than their understanding), contrasted different ideas about learning, and/or offered critiques of their approaches to learning. Variation in the learning experience is essential for reflecting, contrasting, and critiquing one's past and current experiences.

\section{Learning with meaning}

Several students gave evidence that their prior practice as learners of mathematics was centered around memorization and the application of somewhat rote procedures. In contrast, students noted a shift toward understanding, interpretation, and creativity as important parts of learning mathematics with meaning. As discussed previously, as researchers we are limited in our ability to infer what students mean by these terms accurately, but nonetheless we can identify common themes that reflect changes in awareness as evidenced by their reflections on variations in experience. For example, Abel reflected on his understandings of the Uniqueness Theorem and how he had changed his approach to learning in this course:

I knew about the Uniqueness Theorem, you just take the derivative, but I didn't know the meaning of it. Like for this problem it specifically said 'they crash in mid-air' so now when I do problems I really carefully interpret it. (Abel, Presentation)

Brad's reflection below indicates that in this class, learning mathematics is an ongoing and evolving process "building off of what we learn day in and day out." This seems to be in contrast to his previous practice as a learner of mathematics, which we may speculate was a more staccato collection of seemingly disjoint elements. The accompanying excerpt from Enrique's portfolio indicates a sense that, despite solving a series of problems about spring-mass systems, there is more to learn. Again, we see evidence of a belief that learning is a continuous process of growth.

I feel that really encompasses what kind of this class is about and that's building off of what we learn day in and day out. (Brad, Presentation)

I do believe I haven't learned all there is to know about these particular situations. (Enrique, Portfolio)

Derrick reflected on the learning process he experienced in this course as follows: 
I truly believe this [type of learning] is where students can start to reach true potential in learning, where they can actually apply concepts and ideas to other situations and even real life applications. (Derrick, Portfolio)

Here we see a clear reflection on the learning process and an assessment of the value of that process. That this is a major takeaway from the course for him is indicative that this is something he was not previously particularly conscious of or reflective about. He points to the potential of this type of learning to give students the possibility of applying mathematical ideas and procedures across contexts. In the following excerpt, Jimena further reflects on the process of learning with meaning, which she contrasts with instances when students write something down either out of habit or because they are mimicking what their teacher did.

Looking back on this, I've realized something a little more profound than that. I was thinking about how it's a habit for students to put a plus/minus sign in front of their solution to a square root. Do they even know what that means? I mean of course the answer to the square root of 4 is 2 or -2 , but do they know what it means to the problem? For this example, only the negative solution works with the initial condition. I thought about students learning the Pythagorean Theorem. Obviously a triangle wouldn't have a length of -5 as a side. The concept of understanding what you're writing rather than just putting it there because the teacher did it is really important to me. (Jimena, Portfolio)

As evidenced by the following portfolio entries from Enrique, learning with meaning includes thinking creatively and making connections.

[This task] prepared our brains to think creatively and critically in order to solve problems rather than by trying to recall so[me] old trick or technique to solve the problem. (Enrique, Portfolio)

The spring mass systems were an intriguing set of problems that culminated all our growth, knowledge, which highlights our creative thinking, ability to make connections. (Enrique, Portfolio)

In summary, student reflections indicate that learning with meaning for them is interpretative, it is continuous, it is applicable, and it is creative. The fact that they are explicitly aware of these characteristics suggests that their experiences in this class were different from past experience. Moreover, their use of first person expresses a level of agency ("I really carefully interpret it", "building off of what we learn", "I've realized something a little more profound") that is fundamental toward developing a critical stance.

\section{Learning as an active process}

Students also explicitly discussed aspects of the learning process that indicate a growing awareness of their role as active participants, as opposed to passive recipients, in the development of mathematical knowledge.

I had to give a reason for why I chose to go about it a certain route for solving problem[s], which strengthened my knowledge of what mathematical tools to use in certain situations. (Abel, Portfolio) 
I also realized that having [to] explain your answer in an essay format reinforces the techniques needed to solve problems that are similar or that requires the same tools and because of this, in future math classes I will write out explanations for my procedures when taking notes and doing the homework, so when I'm studying for an exam or looking over my notes after a long vacation the technique would seem as if I just learned it yesterday. (Abel, Portfolio)

Being active in the learning process, however, is not a smooth process. Indeed, the theme of productive struggle was particularly salient, with students identifying this phenomenon as an empowering part of their learning. That is, when they worked through mathematically challenging tasks, identifying issues and correcting their own path, they made the judgment that they benefitted mathematically and intellectually. For example, Brad and Derrick are each explicit in their reflections about the value of embracing mistakes.

I learned this semester that it's okay to be wrong and actually being wrong really helps in getting you in the right direction to be right. (Brad, Presentation)

It was productive frustration when I got my homework back and [the teacher] went over the mistakes. (Derrick, portfolio)

In addition to valuing struggle and errors, students reflected on the benefit of putting in a significant amount of time working individually and collectively on challenging tasks.

I found it mind blowing at how much information my group and I could find from this small formula. [...] I found this assignment to be extremely helpful because it required a lot of thought, teamwork, and dedication in order to figure it out and put it together. Because I worked on it so much, I found it to be helpful for the test. (Valencia, Portfolio)

In the previous excerpt, Valencia expressed the emotional reaction of the experience being "mind blowing." The experience of being active in their learning enabled the students to gain a sense of control (i.e., agency) that alleviated the negative emotional response that arises from being passive recipients. This contrasts with learning environments in which students are rather passive and which can fail to provide them with the agency to influence their situation. For example, Denise exhibited control over her anxiety when she shared the following with the class during her presentation:

I was kind of scared of this course when I figured out we were plugging in functions into differential equations just because I was so used to finding a variable so it kind of made me nervous. (Denise, Presentation)

The fact that Denise felt comfortable enough to share this initial fear in her oral presentation suggests that she came to see the classroom community as a space that was safe to express anxiety and fear of mathematics. In her portfolio, Denise further reflected on the status of solutions as functions and noted the growth in her thinking, which indicates a certain level of meta-awareness of her own thinking that often accompanies being active in the learning process.

It was significant to me because I never knew solutions could be functions, so once I realized that it was somewhat astonishing to me. (Denise, Portfolio)

The idea that learning can happen through concerted effort and collaboration, coupled with the idea that challenges are productive and "astonishing," are hallmarks of what we 
generally call active learning. That these students, who are unlikely to have had much experience in active learning environments, have identified this as a key aspect of their learning in this course, and present it as a characteristic of their current and future practice as learners, is heartening. Brad, in describing the learning process, comes quite close to the communities of practice notion of learning as engagement in a community context by emphasizing the learning context:

I believe the best way to learn is to have an environment where a person feels safe, where they know that if they are wrong it's okay, where productive mistakes can happen. (Brad, Portfolio, emphasis added)

We previously quoted him regarding productive struggle, and his conviction that sometimes being "wrong" is a valuable part of eventually being "right." Here he talks about the environment that supports that productive struggle by making it a normal part of the practice of learning. In the same portfolio entry, he says that he was "deeply afraid" of "being wrong" or "being judged for being wrong" at the outset of the course. The expressed shift from a fear of mistakes to valuing them is remarkable, and his description is a clear indication of a critical stance toward learning mathematics.

Students began the differential equations class with a long experience of learning mathematics in school and earlier university courses. They arrived with deeply rooted expectations about learning mathematics and what it feels like to be a learner of mathematics. Their prior experience had led them to expect to be passive recipients of procedures, to be faced with demands for memorization of often meaningless facts, and often this was accompanied by a degree of fear and intimidation. Against this background, the inquirybased mathematics education approach led to a new experience of learning in which mathematics was experienced as meaningful and judged to be deeper. The students were able to accept challenge, productive struggle, and the agency that gave them a sense of control over their own learning and emotional reactions.

\section{Critical stance toward mathematics teaching}

In this section we detail the ways in which the students took a critical stance toward teaching, including past instructional experiences, teaching as experienced in the differential equations course, or imagined future teaching practices. But before doing so we address the question, what is teaching from a community of practice perspective? Wenger's position on teaching is one that eschews a cause and effect relationship. Instead, teaching can be a resource for the emergent, ongoing process of learning. What matters is the "ability of teaching and learning to interact so as to become structuring resources for each other" (Wenger 1998, p. 267). Conceptualizing teaching as structuring resources for learning leads Wenger to pose the following four questions:

1. How can we honor the emergent character of learning?

2. How can we minimize teaching so as to maximize learning?

3. What kind of rhythm and shifts of focus will allow learning and teaching to inform each other?

4. How can we maximize the processes of negotiation of meaning enabled by that interaction? (p. 267) 
In the conclusion, we revisit these four questions related to conceptualizing teaching as a structuring resource for learning and use the critical stances toward mathematics, learning mathematics, and toward teaching offered by students to reflect on these questions.

Our analysis of student portfolios and presentations revealed three different critical stance foci related to mathematics teaching: teaching with meaning, teaching as the negotiation of meaning, and socioemotional concerns. It was the case that the taking up of these three foci varied among the students. Moreover, the portfolios and presentations of three students showed little to no evidence of embracing a critical stance toward teaching. This variation across students is consistent with conceptualizing teaching as a structuring resource because not all students use resources in the same way. Moreover, developing a critical stance is not a march to some predetermined destination, but a personal exploration of past experiences and future aspirations.

\section{A focus on teaching with meaning}

Several students made clear contrasts between the teaching in the differential equations class and their prior mathematical instructional experiences. Their critical stance toward teaching is consistent with their critical stance toward mathematics, which highlighted the shortcomings of an emphasis on routine skills and memorization; this consistency is not surprising based on our conceptualization of the students' trajectory of increasing participation. For example, Abel made the following contrasts:

In our other math classes we were just taught how to solve or do a problem and given symbols ...... but in this class I also learned that derivatives are also used for many situations in math, the derivative can be a rate of change over time or just a rate of change as well as a function. (Abel, Portfolio)

(I)n other math classes they teach us the process for like dy/dt. In linear algebra, our old algebra classes, like they taught us how to take, how to do multiple uses with vectors and stuff, but in this class the professor showed us like what is the significance of it. (Abel, Presentation)

Similarly, Derrick reflected on the importance of teaching for meaning and how he imagines his future work as a teacher.

The biggest thing I am going to take away from this is the importance of building a solid foundation before teaching concepts. When I become a teacher I will make sure to replicate this type of learning in my classroom. I truly believe this is where students can start to reach true potential in learning, where then can actually apply concepts and ideas to other situations and even real life applications, like the presentation we gave. (Derrick, Portfolio)

Derrick's remark about his future students reaching their "true potential in learning" suggests that he sees teaching as an act that facilitates learning and identity formation as co-emergent phenomena, as opposed to a cause and effect relationship. Like Derrick, Jimena also sees her future self engaging in teaching practices that apparently contrast with her previous instructional experiences.

The concept of understanding what you're writing, rather than just putting it there because the teacher did it, is really important to me. With my students, I want to stress the idea of absorbing material rather than regurgitating it. (Jimena, Portfolio) 
In $8^{\text {th }}$ grade, I told myself that I'd never understand how to [insert math word here.] It's students like myself that make me want to teach. Anything can be learned, you just need someone to break it down for you and give you the necessary tools for you to arrive at a conclusion yourself. (Jimena, Portfolio)

In the last excerpt, Jimena emphasizes students "like herself" who might struggle with particular ideas. Rather than being distraught at this experience, the first excerpt indicates that she is inspired to be a resource for students to arrive at conclusions for themselves. Teaching for Jimena, therefore, is not something that should result in students "regurgitating" teacher stated facts, but rather the empowering students with the "necessary tools" to figure things out for themselves. In other words, teaching can be a resource for the emergent, ongoing process of learning.

\section{Teaching as the negotiation of meaning}

As previously indicated in the Theoretical background section, the notion of "joint enterprise" is a core construct in CPT. As described by Wenger (1998) there are three defining aspects of a joint enterprise. First, the enterprise is the outcome of a process of negotiation through the participants' mutual engagement. Second, although in large part the enterprise is determined by structures and forces outside their control, the participants define their day-to-day experience of the enterprise. Third, the enterprise is characterized by mutual accountability where participants are responsible to each other. As we subsequently argue, the following two excerpts from Enrique nicely illustrate all three of these aspects.

This course forces you to think differently in order to solve a problem and if and when you solve the problem the class is designed so that you have to verbally communicate your ideas to the rest of the class and communicate them clearly effectively and convincingly. The reason this course has so much understanding and knowledge being shared is because you are forced to make sense of the problem yourself and once someone understands it they share their ideas and the best way to know you are correct is to hear others' feedback whether or not you have convinced them of your thought process and your answer. (Enrique, Portfolio)

I love the whiteboards for the simple fact that you're able to share your thinking, you can turn them, you can show them, like everything and everybody can see it. (Enrique, Presentation)

In the first excerpt, Enrique speaks to how "the class is designed," which likely refers to the cycles of small group work and whole-class discussion of students' work intended to promote the social norm of communication and sharing of ideas. This "design" is part of the larger structure of interaction patterns in which student work is embedded. In the second excerpt Enrique explains how the whiteboards (every group had a $3^{\prime} \times 4^{\prime}$ $(0.9 \mathrm{~m} \times 1.2 \mathrm{~m})$ whiteboard at their table) provided a material structuring resource that facilitated group collaboration and whole class sharing of ideas. Enrique also points to how the goal of knowing you are correct is negotiated through hearing "others' feedback" and being responsible to this feedback. Thus, mathematical truth is something that is negotiated among students, as opposed to being handed down from the teacher or textbook.

In the first excerpt above Enrique stated that the course "forced you to think differently" and that one is "forced to make sense of the problem yourself." We interpret his use of the word "forced" not in terms of being strong armed where his agency was removed, 
but rather in terms of his participation and contribution to the ongoing constitution of the social norms that students explain their reasoning and make sense of others' reasoning. We also interpret his remarks that the teaching in the class was contrary to his experiences in other classes in which he did not have to think differently or make sense of problems for himself. It is only when one has variation in experience that such a difference in what is expected seems noteworthy.

Enrique also critically reflected on past and current instructional practices, comparing the extent to which there was or was not space for the negotiation of meaning.

To me, I've had some great teachers that are great at explaining things, but I'm there taking down notes, trying to keep up and this guy can talk, read, write, everything at the same time and I'm like which one do I do? Do I take notes or do I pay attention? Usually I pay attention because I don't really like writing. That's one of the things that I really gained from this class is really to have students understand something, you can't just have them writing down notes because if you were taking any other class and someone just showed you a paper of notes you probably would have no idea what was going on. (Enrique, Presentation)

Here we see Enrique acknowledging past great teachers that could "talk, read, write, everything at the same time," but such teaching practice did not invite him into the process of meaning making. He had to choose between writing things down, talking, or paying attention. In contrast, Enrique noted that in the differential equations class to really understand something, "writing down notes" is insufficient. As evidenced in his first two excerpts, what is necessary is teaching that facilitates the negotiation of meaning. But when meaning is negotiated among participants in the classroom, inevitably ideas get voiced that are tentative and on occasion wrong. This leads us to the third focus of students' critical stance toward teaching.

\section{A focus on socioemotional concerns}

While socioemotional concerns are not a prominent feature of the community of practice perspective, we found that for Brad and Jimena the concerns they expressed were about their future teaching. For example, as detailed in the previous section on critical stance toward learning mathematics, Brad offered the critical reflection that he

learned this semester that it's okay to be wrong and actually being wrong really helps in getting you in the right direction to be right and there is nothing wrong with being wrong. (Brad, Presentation)

This insight, which reflects particular social interaction patterns and emotional responses to these patterns, was not only significant for his learning, but also for his imagined future self as a teacher, as evidenced in the following excerpt.

[This new insight about the usefulness in being wrong] is going to help me relate to a lot of, you know high school, if I'm teaching high school, I think to be the best teacher you can be, you've got to be able to relate to your students and I think this is a way that I'm going to be able relate to them so I felt it was, with everything we learned, I thought this was the most important lesson I learned this semester. (Brad, Presentation) 
In addition to the classroom being a safe place for expressing ideas, Jimena expressed the pride of accomplishment and her desire to similarly empower her future students.

So that was one of my most proudest works. I felt like I really understood the question and I understood my answer and I felt that I made really clear connections and I was really proud of it. So that's the experience I want to create for my future students one day. (Jimena, Presentation)

As a case in point, Jimena's agency to be a positive force for her future students cannot be separated from her emerging stance toward mathematics and toward learning. As we documented in the first part on the results section, students negotiated new meanings through developing new relationships between their participation and reification of the mathematics studied. In the second part of the results section, we documented students' emerging appreciation of learning as an active process where mistakes and failures are valuable resources. Consistent with a view of teaching as structuring resources, we find it unlikely that productive insights into teaching with meaning and teaching as the negotiation of meaning would be possible without engaging a critical stance toward mathematics and toward learning.

We note these students intend to gain credentials for teaching. It is well known that the most powerful influence on the practice of novice teachers is their experience as students, what Lortie (1975) refers to as the "apprenticeship of observation." The students' experience in the differential equations class demonstrates that teaching can be different, and they experience how inquiry-based mathematical education can be implemented. The students experienced the minimization of teaching that facilitates the maximization of learning and the approach breaks the self-reinforcing cycle of teaching-learning-teaching.

\section{Conclusion}

In this paper, we advanced CPT, specifically the notion of community of inquiry as a framework for analyzing university mathematics education. As noted in the introduction, there is little empirical work at the university level that embraces a CPT approach, and we posited some reasons why this might be the case. We conjectured that the long-standing tradition of lecture has inhibited such social theorization. However, the move to more inquiry-based learning and teaching at the university level opens up new needs and new possibilities. In particular, inquiry-based mathematics education offers students and teachers alternative experiences in learning and teaching. As we documented, such alternative experiences afford opportunities for participants to reflect critically on their experiences. Analysis of such reflections led to the primary contribution of this paper, namely the development of the notion of critical stance. We claim a significant contribution of this paper is the introduction of the construct "critical stance" as complementary to "critical alignment' that has been developed by Jaworski and others (Biza et al. 2014). Earlier we contrasted 'critical stance' with Wenger's (1998) characterization of 'alignment' as a 'mode of belonging'; stance, we assert, is a mode of 'being' an attitude, perspective or disposition. Critical stance is dependent upon the student's awareness, the information and experience they possess to reach an informed judgment about an issue, and recognition of their agency to make a difference. Critical alignment to a practice relates to a person's relationship with the practice. On the other hand, critical stance also relates to the personal characteristics and attributes that the person brings to their participation. 
The notion of critical stance embraces three components. First, the students must be aware of the possibility that their experiences could be different from what they have previously encountered. This requires that they experience variation in the forms of engagement and participation. Such variation relates to Marton's Variation Theory (Marton and Pang 2013) which highlights the central role of variation in learning. Second, as noted previously, the students must be able to reach some judgment, based on their reflection and evaluation of experience of participation. The students must be able to recognize when one experience of meaning, learning, or teaching is different from another. Third, the students need to be aware of their agency to change things through the manner of their engagement. This third component connects to the construct of awareness as described by Mason and others (Mason 1998; Mason and Davis 2013). In particular, the levels of teacher awareness in action, awareness in discipline, and awareness in counsel support effective teaching. In this paper we provided insight as to how prospective teachers might develop awareness within a community of inquiry through the adoption of a critical stance.

We now return to Wenger's four questions related to conceptualizing teaching as a structuring resource for learning and use the critical stance offered by students to theorize responses to these questions. First, how can we honor the emergent character of learning? We see in student responses ways that this can occur: by focusing on communication, on meaning making, and by working to create an environment where mistakes are valued and seen as productive. Second, how can we minimize teaching so as to maximize learning? As Jimena suggested, meaning is maximized when one seeks understanding as opposed to "just putting it there [in your notes] because the teacher did." Similarly, Enrique rejected the practice of having students "just writing down notes." But these student practices leave open the question of what the teacher did to foster a shift from passively copying down notes to engaging in ideas. Insight into this issue is beyond the scope of this analysis and would require close examination of classroom data over time. Third, what kind of rhythm and shifts of focus will allow learning and teaching to inform each other? To address this question fully, we would need to examine classroom data over time, but we see the following hints of insights from student responses: cycles of small group work and wholeclass discussion, collective small group work on shared whiteboards, student presentations, orchestrating discussion of ideas, and using student thinking. Fourth, how can we maximize the processes of negotiation of meaning enabled by that interaction? We conjecture the key to this lies within discourse patterns including the dialogue patterns that facilitate student to student interaction, and the use of curricular materials that allow space and opportunities for students to reinvent mathematical ideas. Central to this, we suspect is the creation of a safe environment in which it is okay, and even good, to make mistakes.

We note Wenger's caution about designing for learning: "No community can fully design the learning of another. And at the same time: No community can fully design its own learning" (p. 234). This sentiment is an intriguing and relevant one for our study of this class. The teacher, who is part of communities of mathematicians and mathematics educators, certainly designed the course in order to provide students the opportunity to learn differential equations through engagement and negotiation. However, the students participated in conversations relevant to their latent community of prospective mathematics teachers and, at their own behest, engaged in social learning about learning. This lends further support to our suggestion that the inquiry-oriented mathematics classroom can be analyzed as a community of practice, and, as in this paper, as a community of inquiry.

Regarding the limitations of this study, we noted previously that this was a small class of eight students who all intended to teach secondary mathematics, which might influence the depth and nature of classroom discussions. The students' portfolios and presentations 
which we have analyzed here were part of the course itself, to be graded by the instructor. It is unlikely for students in such a situation to say negative things about a course, but it was still unexpected for so many students to go as far as they did. The students spontaneously commented on the nature of their relationship with the teaching and learning of mathematics, which was not an explicit focus of the course. Thus, while we expect that students omitted negative opinions that they might have had, we find their positive statements to be compelling evidence of the existence and possibility of critical stances if not their frequency.

We conclude with a reflection on the course by Enrique, which speaks directly to the value-added of inquiry-based mathematics education. "To me as valuable as all the information about differential equations, bifurcation values, Valencia graphs are to me, I really enjoyed the concept of learning to teach and learning to learn." The social theorization of inquiry-based mathematics education developed here enabled us to explore how such a perspective offered by Enrique is made possible by taking a critical stance toward mathematics, toward learning, and toward teaching.

Acknowledgements Open Access funding provided by University of Agder.

Open Access This article is licensed under a Creative Commons Attribution 4.0 International License, which permits use, sharing, adaptation, distribution and reproduction in any medium or format, as long as you give appropriate credit to the original author(s) and the source, provide a link to the Creative Commons licence, and indicate if changes were made. The images or other third party material in this article are included in the article's Creative Commons licence, unless indicated otherwise in a credit line to the material. If material is not included in the article's Creative Commons licence and your intended use is not permitted by statutory regulation or exceeds the permitted use, you will need to obtain permission directly from the copyright holder. To view a copy of this licence, visit http://creativecommons.org/licenses/by/4.0/.

\section{References}

Biza, I., Jaworski, B., \& Hemmi, K. (2014). Communities in university mathematics. Research in Mathematics Education, 16(2), 161-176.

Braun, V., \& Clarke, V. (2006). Using thematic analysis in psychology. Qualitative Research in Psychology, 3(2), 77-101.

Common Core State Standards Initiative (CCSSI). (2010). National Governors Association Center for Best Practices and Council of Chief State School Officers. https://www.corestandards.org/assets/CCSSI _Math\%20Standards.pdf. Accessed 27 November 2019.

Conference Board of the Mathematical Sciences. (2016). Active learning in post-secondary mathematics education. Washington, DC: Conference Board of the Mathematical Sciences.

Curzon-Hobson, A. (2003). Higher learning and the critical stance. Studies in Higher Education, 28(2), 201-212.

Freudenthal, H. (1991). Revisiting mathematics education. Dordrecht: Kluwer Academic Publishers.

Goodchild, S. (2014). Theorising community of practice and community of inquiry in the context of teaching-learning mathematics at university. Research in Mathematics Education, 16(2), 177-181.

Goos, M., \& Bennison, A. (2008). Developing a communal identity as beginning teachers of mathematics: Emergence of an online community of practice. Journal of Mathematics Teacher Education, 11, 41-60.

Gravemeijer, K. (1999). How emergent models may foster the constitution of formal mathematics. Mathematical Thinking and Learning, 1, 155-177.

Holton, D. (Ed.). (2001). The Teaching and Learning of Mathematics at University Level An ICMI Study. NY: Kluwer Academic Publishers.

Jaworski, B. (2006). Theory and practice in mathematics teaching development: Critical inquiry as a mode of learning in teaching. Journal of Mathematics Teacher Education, 9, 187-211. 
Jaworski, B., \& Matthews, J. (2011). How we teach mathematics: Discourses on/in university teaching. In M. Pytlak, \& T. Rowland (Eds.), Proceedings of the 7th Conference of European Research in Mathematics Education (CERME7) (pp. 2022-2032). Rzeszów, Poland: ERME.

Laursen, S., \& Rasmussen, C. (2019). I on the prize: Inquiry approaches in undergraduate mathematics education. International Journal of Research in Undergraduate Mathematics Education, 5(1), 129-149.

Lave, J., \& Wenger, E. (1991). Situated learning: Legitimate peripheral participation. Cambridge: Cambridge University Press.

London Mathematical Society. (2010). Mathematics degrees, their teaching and assessment. London Mathematical Society. https://www.lms.ac.uk/sites/lms.ac.uk/files/About_Us/news/2010-04\%20LMS\%20Tea ching\%20postition\%20statement\%20(14\%20April).pdf. Accessed 7 October 2017.

Lortie, D. (1975). Schoolteacher: A sociological study. London: University of Chicago Press.

Marton, F., \& Pang, M. F. (2013). Meanings are acquired from experiencing differences against a background of sameness, rather than from experiencing sameness against a background of difference: Putting a conjecture to test by embedding it into a pedagogical tool. Frontline Learning Research, 1(1), 24-41.

Mason, J. (1998). Enabling teachers to be real teachers: Necessary levels of awareness and structure of attention. Journal of Mathematics Teacher Education, 1, 243-267.

Mason, J., \& Davis, B. (2013). The importance of teachers' mathematical awareness for in-the-moment pedagogy. Canadian Journal of Science, Mathematics and Technology, 13, 182-197.

Mathematical Association of America (MAA). (2017). MAA Instructional Practice Guide. Washington, DC: Mathematical Association of America. https://www.maa.org/programsand-communities/curri culum\%20resources/instructional-practices-guide. Accessed 16 August 2018.

Nickerson, S. D., \& Moriarty, G. (2005). Professional communities in the context of teachers' professional lives: A case of mathematics specialists. Journal of Mathematics Teacher Education, 8, 113-140.

Rasmussen, C., \& Kwon, O. (2007). An inquiry oriented approach to undergraduate mathematics. Journal of Mathematical Behavior, 26, 189-194.

Rasmussen, C., Dunmyre, J., Fortune, N., \& Keene, K. (2019). Modeling as a means to develop new ideas: The case of reinventing a bifurcation diagram. PRIMUS, 29(6), 509-526.

Rasmussen, C., Keene, K. A., Dunmyre, J., \& Fortune, N. (2017). Inquiry oriented differential equations: Course materials. Available at https://iode.wordpress.ncsu.edu. This work is licensed under a http:// creativecommons.org/licenses/by-nc-sa/4.0/ Creative Commons Attribution-NonCommercial-ShareAlike 4.0 International License. Accessed 23 Nov 2019.

Rasmussen, C., Zandieh, M., \& Wawro, M. (2009). How do you know which way the arrows go? The emergence and brokering of a classroom mathematics practice. In W.-M. Roth (Ed.), Mathematical representations at the interface of the body and culture (pp. 171-218). Charlotte, NC: Information Age Publishing.

Saxe, K., \& Braddy, L. (2015). A common vision for undergraduate mathematical sciences programs in 2025. Washington, DC: Mathematical Association of America.

Solomon, Y. (2007). Not belonging? What makes a functional learner identity in undergraduate mathematics? Studies in Higher Education, 32, 79-96.

Solomon, Y., Eriksen, E., Smestad, B., Rodal, C., \& Bjerke, A. H. (2017). Prospective teachers navigating intersecting communities of practice: Early school placement. Journal of Mathematics Teacher Education, 20, 141-158.

Stains, M., Harshman, J., Barker, M. K., Chasteen, S. V., Cole, R., et al. (2018). Anatomy of STEM teaching in North American universities. Science, 359(6383), 1468-1470.

Ticknor, C. S. (2012). Situated learning in an abstract algebra classroom. Educational Studies in Mathematics, 81(3), 307-323.

Viirman, O. (2018). Characteristics of participation-A mathematician and a mathematics educator collaborating on a developmental research project. In V. Durand-Guerrier, R. Hochmuth, S. Goodchild, \& N. M. Hogstad (Eds.), Proceedings of INDRUM 2018: Second conference of the International Network for Didactic Research in University Mathematics (pp. 442-451). Kristiansand, Norway: University of Agder and INDRUM.

Wenger, E. (1998). Communities of practice: Learning, meaning, and identity. Cambridge: Cambridge University Press.

Yackel, E., \& Cobb, P. (1996). Sociomathematical norms, argumentation, and autonomy in mathematics. Journal for Research in Mathematics Education, 27, 458-477.

Zaslavsky, O., \& Leikin, R. (2004). Professional development of mathematics teacher educators: Growth through practice. Journal of Mathematics Teacher Education, 7, 5-32. 
Publisher's Note Springer Nature remains neutral with regard to jurisdictional claims in published maps and institutional affiliations. 